\title{
Editorial: labor markets, inequality and the welfare state
}

\author{
Selected papers from the 2009 Annual Meeting of the Austrian \\ Economic Association
}

\author{
Johann K. Brunner • Gerald J. Pruckner
}

Published online: 10 April 2010

(C) Springer Science+Business Media, LLC. 2010

NOeG 2009, the Annual Meeting of the Austrian Economic Association, took place from May 22 to 23 at the Johannes Kepler University of Linz and was organized by the Department of Economics. The main topic of the conference reflects one of the major research areas of the Department members, which is also documented by the fact that the Department heads the "The Austrian Center for Labor Economics and the Analysis of the Welfare State", a National Research Network financed by the Austrian Science Fund (FWF).

The primary motivation for research in this area comes from the fact that in many industrialized countries, with Austria as a particularly good example, considerable resources are transferred via welfare-state institutions, which provide insurance against risks such as unemployment, disability and illness, or old age. Obviously, these transfers and their financing have important effects on individual behavior, especially on labor supply, but also on the distribution of income. Moreover, one can expect that the welfare state will be confronted with big challenges in the future. In the short run, the consequences of the actual economic crisis for the unemployed must be mitigated, while in the longer run potential losses from globalization, occurring for specific groups, may call for sufficient social assistance. Above all, demographic changes will cause serious strain. In view of this, the question of how to design appropriate rules guiding the transfer of resources, and how to evaluate their consequences is a continuing task of economic policy.

The significance of ongoing research efforts was clearly demonstrated in the plenary sessions of the conference, with invited lectures by David Card (Immigration and Inequality), Eddy van Doorslaer (Socioeconomic Differences in Health over the Life Cycle: Evidence and Explanations) and Giacomo Corneo (Income

J. K. Brunner $(\bowtie) \cdot$ G. J. Pruckner

Department of Economics, University of Linz, Altenberger Straße 69, 4040 Linz, Austria

e-mail: johann.brunner@jku.at

G. J. Pruckner

e-mail: gerald.pruckner@jku.at 
Concentration: Theory and Evidence). From the general sessions a number of papers, which were of relevance for the main topic of the conference, were solicited for submission to Empirica. They went through a usual refereeing process and five of them are published in this Volume. The selected papers illustrate very well the various important issues that were addressed in the sessions.

Naturally, recent developments in the labor market and their influence on wages represented one central topic of the conference. In the first paper, Pointner and Stiglbauer deal with the trend in the distribution of wages in Austria. This is a particularly important issue, as in the last decades there was a clear trend towards a larger dispersion of wages in many OECD countries. A prominent explanation for this refers to the demand side, stating that demand for skilled labor relative to unskilled labor has grown. Another potential cause can be identified as developments on the supply side, such as a higher labor participation by female workers or a changing age structure of the workforce. Pointner and Stiglbauer use data from the European Structure of Earnings Survey, a firm survey on individual earnings, and compare the years 1996 and 2002. Though only a modest overall increase of wage inequality occurred in this period, by applying a suitable decomposition procedure the authors reveal a number of interesting changes that have been at work, affecting both the characteristics of the workplaces and of the workers.

Among others trade unions have continuously argued that globalization and trade openness may have a detrimental impact on domestic wages. In their contribution Éva Katalin Polgár and Julia Woerz discuss the role of openness to trade for industry wages in the enlarged European Union. Based on panel data for EU-25 countries at the industry level (15 manufactoring and 6 service industries) for the period of 1995-2005 the authors find that the relationship between trade and wages is in most cases positive, but that the economic impact is rather small. The authors conclude from this result that trade cannot be seen as a decisive factor for wage formation, and that trade openness is no real threat to wages in the EU-15. Even though average effects are small, a negative relation is found for some industries in the EU-15. Especially resource-based sectors in this group of countries may suffer from an increase in integration. As a consequence, this requires a careful design of economic policy whenever questions of trade integration are being addressed.

One paper presented in the health economics session has focused on the relationship between workers' health and their working conditions. In his contribution, Thomas Leoni analyses the determinants of health and safety risk perceptions in the workplace. The relevance of this question for labor market policy seems obvious: whenever subjective measures of job-related risks are being used, differences in risk perceptions may influence the calculation of wage differentials and values of statistical life. Moreover, the perceptions of job-related health and safety risks will influence workers' occupational choices and their demand for safety, and thus help explain labor market segmentation. Using data from the European Working Conditions Survey the author finds that perceptions of workplace risks are strongly correlated with onerous job characteristics and hazardous working conditions. Moreover, not only the exposure to dangerous substances and other environmental factors but also stress and psychically demanding working conditions induce workers to perceive their occupation as dangerous. And finally, the analysis finds strong 
correlations of risk perception with personal characteristics such as age, education, work experience and family responsibilities.

A particularly important long-term trend in the structure of the workforce comes from the process of aging in many industrialized countries, mainly due to a decline in fertility rates. This trend is expected to have severe consequences for the costs of many achievements of the welfare state, such as public pensions or the health care system. A major question for their financing is how aging will affect economic growth and capital formation. In their contribution, Prettner and Prskawetz concentrate on the effect of decreasing fertility on average productivity and on the distribution of income with respect to young versus old workers. They construct a neoclassical overlapping-generations model, where the important decisions are made by young adults, who determine the number and the education of their offsprings, and by old workers, who save for retirement. In addition to human and physical capital formation, the model takes learning effects as well as depreciation of knowledge into account. The authors find that a lower fertility rate goes along with higher production per-capita, while consequences for the income distribution depend strongly on substitutability between young and old workers.

It is well-known that Austria belongs to the group of countries with a particularly large share of the public sector in the economy. Public activities typically involve some element of redistribution, most notably the transfer payments by the various welfare state institutions, aimed at assisting those individuals who either have experienced an adverse event or are disadvantaged by nature. It is obvious that such a high level of redistribution could not be sustained without a sufficient agreement on the side of the voters. In the final paper of this Volume, Andreas Kuhn analyzes what determines the demand for redistribution in the Austrian population. He uses data for Austria from the International Social Survey Program and focuses on the respondents' subjective estimates of the wages of different occupational groups, as well as on their own view of what would be the "right" or "just" wage of these groups. The result may indeed explain the Austrian situation: it turns out that most individuals would prefer a more equal distribution of wages than they perceive to actually exist. Moreover, individuals who demand more redistribution also tend to be more favourable towards the welfare state. 